\title{
CORTÉS OU BERNAL DÍAZ? \\ O MISTÉRIO SOBRE O VERDADEIRO AUTOR DE \\ HISTORIA VERDADERA DE LA CONQUISTA DE NUEVA ESPAÑA
}

Dóris Helena Soares da Silva Giacomolli ${ }^{1}$

RESUMO: Existe um texto de representações impressionantes ao estilo de epopeia e nele está um acionador para conhecer e, por que não dizer, compreender o que foi a conquista do México. Christian Duverger (2014) dedicou-se a estudar a autoria de História Verdadera de La conquista de la Nueva España, de Bernal Díaz Del Castillo. Esse exame crítico das figuras de Hernán Cortés e Bernal Díaz del Castillo vem auxiliar no exame das versões históricas que incidem não apenas nas batalhas da conquista como, igualmente, em seus personagens. Em Cortés e seu duplo-pesquisa sobre uma mistificação, Duverger questiona a autoria de uma das principais fontes de pesquisa sobre o período, o livro de Bernal Díaz Del Castillo.

PALAVRAS-CHAVE: Christian Duverger. Cortés e seu duplo-pesquisa sobre uma mistificação. Historia verdadera de la conquista de la Nueva-España. Bernal Díaz del Castillo. Hernán Cortés.

\section{Introdução}

Em Cortés e seu duplo Duverger (2014) problematiza os relatos da conquista e, em particular, questiona a autoria de uma das principais fontes de pesquisa sobre o período da conquista do império asteca e das terras do Novo Mundo: Historia verdadera de la conquista de Nueva España.

\footnotetext{
${ }^{1}$ Doutoranda em História da Literatura pela FURG. Mestre em Literatura Comparada pela Universidade Federal de Pelotas (UFPel).
} 
Maria Emília Granduque José (2014), em uma entrevista concedida a ela pelo renomado historiador francês Christian Duverger, explica um dos motivos pelos quais Cortés pode ser o autor do livro que se confere a Bernal Díaz Del Castillo:

Cortés esteve envolvido, no final de sua vida, com a escrita oculta de uma obra dedicada a contar a história da conquista espanhola no México. A obra em questão é nada mais do que a própria Historia verdadera de la conquista de Nueva España, então atribuída ao soldado espanhol Bernal Díaz del Castillo. Considerando que Cortés estava proibido por cédula real de escrever e que suas Cartas de Relación, publicadas entre 1519 e 1526, deixaram de circular após serem censuradas, Duverger sugere que o conquistador criou um narrador fictício, aos moldes de um soldado anônimo que supostamente fez parte do grupo espanhol que esteve nas Índias, com o intuito de deixar registrada a memória de seus feitos empreendidos no México. (JOSÉ, 2014, p. 537, grifo nosso).

Christian Durverger explica que "há uma construção na história feita pelos historiadores e que devemos desconstruí-la, considerando também porque se construiu assim o mito Bernal Díaz e a imagem de Cortés.” (JOSÉ, 2014, p. 546) e que nos acostumamos a pensar, e crer, nos historiadores do século XIX e não nos atrevemos a questionar inteiramente o que eles escreveram. Ele ressalta também que "a historiografia aceitou Bernal Díaz como autor sem fazer uma investigação, sem apurar se realmente o personagem era capaz de ser o autor." (JOSÉ, 2014, p. 541).

A pesquisa de Duverger (2014, p. 14) nos diz que o manuscrito de Bernal Díaz nos chegou através de três documentos distintos, dois manuscritos e um livro publicado em 1632. Um dos manuscritos, o manuscrito da Guatemala, nem autografado, nem original, é publicado em 1904; o segundo é encontrado misteriosamente na Espanha, em 1930.

Seguindo pistas em manuscritos, documentos e algumas inexplicáveis cópias, cuja origem e autoria permanecem incógnitas, surgem algumas questões embaçadas e dúvidas sobre a autoria de História Verdadera de La conquista de la Nueva España, que, segundo Duverger (2007, p. 11) ocupa lugar na literatura hispânica entre Cid e Dom Quixote e que foi 
escrita com a intenção de se se tornar uma crônica elogiosa a Cortés e contestar o livro de Gómara ${ }^{2}$ sobre o qual Bernal Díaz discordava em muitos pontos.

\section{1- No rastro de Bernal Díaz de Del Castillo}

O autor de Cortés e seu duplo-pesquisa sobre uma mistificação levanta questões sobre as divergências e ocultações sobre a biografia de Del Castillo, autor de um único texto, que vão desde o ano de seu nascimento, entre incertos 1484 e/ou 1496, sua cidade natal, Medina Del Campo, apesar de não haver nenhuma pista de que tenha realmente nascido lá. Seu pai não era Francisco Díaz del Castillo, porque o sobrenome Del Castillo, o autor acrescenta somente muito mais tarde, em 1552 (DUVERGER, 2014, p. 45). O mais interessante é que Duverger (2014) afirma que apesar de a conquista do México ter sido amplamente documentada, 1850 páginas de “documentos cortesianos” e de não possuir buraco negro historiográfico, "não se encontra em lugar algum o rastro de Bernal Díaz" (DUVERGER, 2014, p. 55). E deveria haver, já que, na História verídica, Díaz se descreve como um ajudante de Hernán Cortés, sempre presente onde quer que esse se encontrasse, mas, contraditoriamente: "Nenhuma linha, nem a menor menção a Díaz Del Castillo nos escritos de Cortés” (DUVERGER, 2014, p. 56). Igualmente, “as outras crônicas são igualmente mudas. Ninguém cita Bernal Díaz como ator da conquista” (DUVERGER, 2014, p. 57).

Maria Emília Granduque José (2014), questiona Duverger sobre essa questão da autoria de Historia verdadera de la conquista de Nueva España. Duverger explica que concluiu, depois da longa pesquisa, que todos os indícios recolhidos convergem para o nome do próprio Cortés, e não de Bernal Díaz como o autor do livro. A entrevistadora diz que, se pensarmos em termos do século XVI, a questão da autoria não era um problema a ser questionado e que não havia uma preocupação com a originalidade do texto e de seu autor.

\footnotetext{
2 Secretário e biógrafo de Hernán Cortés. No ano de 1554, escreveu La conquista do México, para registrar os acontecimentos do Novo Mundo.
} 
Ela pergunta a Duverger como era essa questão, considerando a época em que viveram Cortés e Bernal Díaz, que responde:

Havia inquietudes e dúvidas entre os historiadores, mas não se questionou profundamente a autoria de Bernal Díaz até a publicação do meu livro. Porque, finalmente, a mistificação foi bem feita, quando há mistificações mal feitas, as dúvidas são mais evidentes. Mas nesse caso foi muito bem feita, havia verdades sobre a história de Bernal Díaz. O que meu livro põe em evidência é que nem a melhor biografia colocou em dúvida essa questão, a historiografia aceitou Bernal Díaz como autor sem fazer uma investigação, sem apurar se realmente o personagem era capaz de ser o autor. O interessante é que os prefácios e os prólogos trazem sempre a mesma informação, que nunca são comprovadas, como uma espécie de repetição de dados. O que me chamou a atenção foi a ausência de uma biografia sobre Bernal Díaz, pois havia elementos de sua família. Mas relacionar a existência de um tal Bernal Díaz na Guatemala é uma coisa, dizer que ele é o autor da crônica é outra coisa. Então, o que nos faltava saber em primeiro lugar é se Bernal Díaz sabia escrever - e quanto a isso não temos prova nenhuma - e como ele pôde escrever uma história tão precisa quarenta anos depois dos fatos. Esse ponto que é preciso contestar e aí está a origem da minha pesquisa. Minha ideia é que a historiografia nunca nos deu uma prova capaz de relacionar Bernal Díaz à autoria da Historia verdadera... Por exemplo, temos duas ou três páginas sobre a vida de Bernal Díaz del Castillo nos prólogos que apresentam a obra, mas, na edição de Porrúa, que é uma edição popular do México, ainda utiliza um prólogo escrito em 1936. Por qual razão? Porque, provavelmente, os que tentaram fazê-lo desisitiram, por ser bastante difícil, preferindo, ao final, reutilizar esse prólogo já pronto, de 1936. Estamos em 2014 e até hoje as casas editoriais publicam um texto de Bernal Díaz, de 1936. Isso significa que sua biografia é impossivel, ou seja, é mais fácil repetir do que adentrar na obscuridade que envolve a sua vida (JOSÉ, 2014, p. 541, grifo nosso).

Diz Duverger (2014) que Cortés fez uma lista dos 21 homens que desembarcaram em Chalchiucuecan, e mais tarde, para se eleger capitão geral e juiz supremo fez um documento lavrado e nele não consta o nome de Bernal Díaz entre os que votaram; na carta que 
Cortés escreveu a Carlos V depois de La Noche Triste ${ }^{3}$ há a ratificação da nomeação de Cortés e nela assinam 544 de seus homens: a de Bernal Díaz não consta entre elas. Há um imenso arquivo que se refere à acusação de Cortés, o juicio de residencia, comandado por Carlos V, com o intuito de destituir Cortés, em 1529 e todos seus colaboradores são testemunhas nesse processo, exceto Bernal Díaz.

\section{2- Astúcia ou modéstia?}

Afirma Duverger que o filho de Bernal Díaz, Francisco, teria inventado um mito para seu pai e "transforma Bernal em escritor"; em Santiago de Guatemala, no dia 22 de fevereiro de 1579, quando Bernal “tornou-se pela primeira vez o autor de História verídica." (DUVERGER, 2014, p. 72-73).

Duverger (2014) ressalta que a erudição de Bernal Díaz del Castillo não condiz com alguém que se autoproclama inculto, iletrado e soldado rude, pois apresenta conhecimentos da cultura bíblica, latina, conhece Homero, cita Alexandre, o grande, por seu nome literário em francês, difundido somente em círculos restritos, remete a eventos acontecidos no século $\mathrm{V}$.

Não resta dúvida que esta poderia ser o que se chama de falsa modéstia, o que é não é incomum, na literatura, que escritores assim se descrevam por não terem tido a educação formal dos mosteiros, mas, ao fazer uma leitura minuciosa de História Verdadera de La conquista de la Nueva España, se percebe que o autor possuía uma cultura espantosa e inexplicável. Duverger (2014) lista inúmeros exemplos desse conhecimento. Quando Cortés monta seu cerco naval para invadir Tenochtitlán ${ }^{4}$, faz um discurso a seus homens, relacionando esse evento ao da prisão, pelos romanos, de Jugurta, rei dos numídias. Duverger analisa a situação de simetria perfeita das duas situações, mas percebe a impossibilidade de

\footnotetext{
${ }^{3}$ Os ataques astecas não cessaram e os espanhóis resolveram fugir à noite, até que foram descobertos e começou outra grande batalha onde metade do exército de Cortez é morto, seria a Notche Triste. (MORAIS, 2006, p. 9).

${ }^{4}$ Capital do império asteca, mais tarde foi nomeada México, pelos espanhóis.
} 
Bernal saber de inúmeros detalhes, de memória, do evento acontecido em Roma e relacioná-los ao discurso de Cortés e lembrar-se de fazer esse paralelo, ao descrevê-lo tantos anos depois: "O caso se complica no problema da cultura - ou da memória- de Díaz del Castillo. Pois o texto de História Verídica entra nesse episódio de Roma com uma precisão muito grande. Menciona-se que Mário foi cônsul por sete vezes, que era natural de Arpino, que Jugurta era o genro do rei Boco, etc”. (DUVERGER, 2014, p. 121). Bernal teria que ser dono de uma memória excepcional, além da cultura espantosa.

Duverger ressalta, então, que Bernal percebe a importância das riquezas enviadas ao rei espanhol e relaciona-as às riquezas que o Rei Salomão usou para construir um templo em Jerusalém e que foram trazidas das ilhas de Tarsis, Ofir e Saba. No capítulo denominado Cidade do México torna-se um circo romano de A história do Conquista da Nova Espanha, Bernal Díaz Del Castillo escreve: "Desde que o sábio rei Salomão construiu e mandou construir o Templo Sagrado de Jerusalém com o ouro e a prata que eles trouxeram das ilhas de Társis, Ophir e Saba, nunca foi relatado quaisquer escritos antigos mais ouro e prata e riquezas do que o que tem sido diário para Castela destas terras” (DEL CASTILLO, 2008, p. 369), (DEL CASTILLO, 2008, p. 369). ${ }^{5}$ Duverger escreve sobre esse conhecimento do autor: "Na verdade, a cultura bíblica de nosso autor não é desprezível." (DUVERGER, 2014, p. 122).

Duverger (2014) lista mais conhecimentos específicos de Bernal Del castillo, a saber: Segundo livro das Crônicas, reino de Saba, história romana, Júlio César e seu livro Comentários da guerra de Gália, edição raríssima traduzida para o espanhol; é capaz de citar o imperador Augusto, Pompeia, Cipião, Aníbal e Mitrítades. Diz-nos Duverger:

Seria possível pensar que conhecer Homero era componente obrigatório da cultura da época. O que é correto, à condição, no entanto,

${ }^{5}$ Chapter Mexico City Becomes a Roman Circus The History of the Conquest of New Spain by Bernal Diaz del Castillo: "Since the wise King Solomon built and ordered to be constructed the Holy Temple of Jerusalem with the gold and silver which they brought him from the Islands of Tarsis, Ophir and Saba, there has never been reported in any ancient writings more gold and silver and riches than what has gone daily to Castile from these lands." (DEL CASTILLO, 2008, p. 369) 
de ser helenista. Ora, fica excluído que Bernal tivesse podido conhecer a língua grega. Então, poderíamos crer, talvez cite Heitor por ouvir dizer, como um personagem lendário de quem se repete o nome para evocar virtudes guerreiras [...] No entanto, quando Díaz compara o descobridor do Colorado, Francisco Vázquez de Coronado, a Ulisses, ele o faz com precisão, sem que o toque erudito pareça forçado. [...]Atena tem olhos imensos, Aurora dedos de rosa, Aquiles é rápido, Telêmaco é sábio. (DUVERGER, 2014, p. 125127).

Bernal continua citando Alarico, rei dos visigodos, Átila, o Flagelo de Deus, evoca o século $\mathrm{V}$ e a luta entre a horda dos hunos, os romanos de Aécio, os francos de Meroveu e os visigodos de Teodorico. Esses conhecimentos não estavam à disposição do soldado de Hernán Cortés.

Há ainda muitas outras dúvidas, nomes e dados exatos de todos os companheiros da expedição, nome da esposa de Pánfilo de Narváez, nome de um mordomo do vice-rei Mendoza, (DUVERGER, 2014, p. 141), as revelações detalhadas sobre Malinche, uma epígrafe num presente que Cortés manda a Carlos V. Assim, Duverger chega a uma conclusão: "Bernal Díaz, veterano da conquista e desfrutando em paz seus dias na Guatemala, não e o autor de História Verídica” (DUVERGER, 2014, p. 136).

Essa afirmação pode ser estonteante para os historiadores e para todos que estudaram suas oposições e contraposições a Gómara, que se postaram do lado de um ou de outro, que defenderam um ou outro.

E para dar mais ênfase a sua versão, o pesquisador afirma que a assinatura de Bernal Díaz que consta na versão manuscrita terminada na Guatemala em 14 de novembro de 1605 seria considerada unanimemente falsa: "Essa assinatura, aposta no final do manuscrito como se fosse para autenticá-lo, como se fosse para credenciar seu valor autógrafo, e com toda evidência uma falsificação” (DUVERGER, 2014, p. 149).

Duverger continua encontrando dificuldades para que Bernal se inscrevesse como dono de tanta cultura: ao mencionar La Noche Triste, o autor faz um paralelo com o incêndio de Roma e cita um poema não tão conhecido, além de outros exercícios de estilo. Duverger 
(2014) afirma que: “ou somos forçados a admirar a fabulosa memória do escritor, que cinquenta anos mais tarde, se lembra, ao pé da letra, de todas essas citações; ou admitimos estar em presença de um procedimento de escritor reconstituindo a posteriori cenas imaginárias para dar vida a sua narrativa" (DUVERGER, 2014, p. 135). O autor tem conhecimentos que somente teriam sido adquiridos se fosse aristocrata ou componente do clero: "Na Espanha medieval do final do século XV, existiam duas maneiras, e apenas duas, de obter esse tipo de educação fundamentada no latim, na literatura antiga e nas Sagradas escrituras" (DUVERGER, 2014, p. 136). Afirma peremptoriamente o pesquisador: “Todas essas considerações tendem a desqualificar o vereador de Santiago como autor de História verídica" (DUVERGER, 2014, p. 136).

Ele nos fala que esse Bernal da lenda, autor de História Verdadera de La conquista de la Nueva España e que alguns historiadores chamam de inventor do romance moderno, escreveu uma carta, repetitiva e confusa, a Carlos V, em 22 de fevereiro de 1552, com a intenção de apresentar queixas contra corrupção, nepotismo dentre outros crimes que seriam praticados pelo presidente da Audiência dos Confins, Alonso López Cerrato. Nessa carta, Bernal se confessa iletrado, o que para Duverger (2014) encaminha-se para se revelar um quase analfabeto, visto ainda que há mais cartas de Bernal que certamente teriam sido escritas por terceiros. O que não resta dúvida é que Bernal sabia assinar seu nome, pois em 1544 assinou um recibo ao receber o dote da esposa, Tereza Becerra, apesar de esta e outras assinaturas De Bernal tenham uma grafia perpetuamente mudada e às vezes ele assina Díaz, e em outras vezes, Díaz del Castillo. Duverger conclui, após ter estudado 153 assinaturas de Bernal Díaz, que foram escritas mesmo por ele, mas que este treinou sua assinatura, somente não se tornou apto a reconstitui-la sistematicamente (DUVERGER, 2014, p. 144152).

E, então Duverger (2014) assevera que sua pesquisa desqualifica Bernal Díaz como autor e afirma: "Tudo nos leva a crer que Bernal Díaz del Castillo nunca escreveu nada, pois nunca soube escrever. Em todo caso, não suficientemente para compor História 
verídica” (DUVERGER, 2014, p. 153). E ele continua sua pesquisa, a procurar o autor misterioso que tem tanto talento para escrever, tanta facilidade com a prosódia e tamanha competência linguística. O pesquisador intenta compreender a mistificação literária que cerca a obra, já que ele nos afirma que quem a escreveu era dono de uma espantosa memória para compilar tantas informações, ou de um arquivo impressionante.

\section{3- Amigo íntimo ou pseudônimo?}

Lendo História Verdadera de La conquista de la Nueva se compreende que o autor possuía muitas informações que afirmava ouvir, privilegiadamente, diretamente de Hernán Cortés e que era, portanto, seu íntimo. Como Bernal Díaz não está documentado como próximo a ele, o enigma se agiganta: como poderia ser capaz até mesmo de julgá-lo, em diversos momentos, se não fazia parte de seu círculo pessoal? E Duverger (2014) chega até onde sua pesquisa se dirigia: ao verdadeiro autor, o homem que possuía todos os motivos e condições para escrever a História Verdadera: Hernán Cortés: “O Cortés em pessoa” (DUVERGER, 2014, p. 171).

Não parece estranho que Cortés tenha decidido escrever sua própria história, a verdadeira, ou que ele considerasse verdadeira; ou, talvez, o que é mais provável, aquela que ele queria que fosse passada para a posteridade, e de que maneira queria que seus feitos e suas razões fossem passados à posteridade.

Assim nos explica Duverger:

Em Monzón, no ano de 1542, o imperador tivera a infelicidade de dizer a Cortés, tête-à tête, que, de toda maneira, as conquistas das quais se vangloriava não eram suas. Tais propósitos constituem uma chocante deformação da história, um desafio à verdade. E Cortés é tomado por uma dúvida: no fundo, não seria possível escrever uma história apócrifa, que negaria completamente a verdade, inventando, por exemplo, que ele nunca teria posto os pés no México e que não seria o autor da conquista da Nova Espanha? O desaparecimento das Cartas de relación, condenadas à fogueira, seria, nessa intenção, um primeiro passo para uma falsificação da história. (DUVERGER, 2014, p. 191). 
Em março de 1527, Cortés é proibido de escrever. A Coroa espanhola emite uma ordem e todos os escritos de Cortés começam a ser apreendidos e queimados. Talvez a intenção fosse mesmo mudar o rumo da história, tirar Hernán Cortés dos epítomes históricos. Vale lembrar que mais obras sobre a "conquista" foram proibidas:

As obras Historia general de las Indias e Historia de la conquista de México de Francisco López de Gómora foram impedidas de circular em $1553[. .$.$] Ao que tudo indica, as causas foram os excessivos elogios$ a Cortés e os possíveis enganos cometidos pelo autor sobre fatos da conquista. Anos depois, foi a Historia general de las cosas de Nueva España de Bernardino de Sahagún que sofreu o silêncio pela censura de Felipe II. (JOSÉ, 2011, p. 26).

Terá sido assim que o espanhol Hernán Cortés decidiu criar, recriar o que era real? Apresentar sua história da maneira que queria que a historiografia a registrasse? Era assim que se queria representado a posterior? Independentemente da verdade, já que "qualquer história é sempre a história de alguém, contada por alguém, a partir de um ponto de vista parcial" (APLEBY et all, 1995, p. 11), queria que o que estava escrito fosse tido por verdade absoluta ao criar uma obra e dar-lhe o título História Verdadera de La conquista de la Nueva España? Não há dúvidas que Cortés sempre teve intenção de criar sua própria imagem, nós sabemos, pois isso fica claro em suas Cartas de Relácion em que ele precisa defender-se e outorgar legitimidade a seus atos, perante o rei espanhol:

A primeira imagem construída a respeito de Hernán Cortés foi escrita por Hernán Cortés, a partir de suas correspondências endereçadas ao monarca espanhol. A Cortés interessava, sobretudo, o objetivo de sua empresa, as circunstâncias táticas e os aspectos sociais e políticos que se relacionavam com sua conquista. Para o capitão espanhol, era preciso descrever seus maiores feitos, em busca de reconhecimento real e isso ele fez até seus últimos dias de vida. $O$ fato de ter sido protagonista e testemunha ocular dos episódios que descreveu garante muito crédito à narrativa de Cortés. Nesse sentido, os relatos de viajantes sempre trazem a ideia de observador, do "eu estive lá" e esse eu vi, do ponto de vista da enunciação, dá crédito a um 'eu digo', na medida em que digo o que vi. O invisível, para vocês, eu torno 'visível' através do meu discurso. (PORTUGAL; MORAIS, 2010, p. 88). 
Quando o escritor afirma ter visto e presenciado o acontecimento, isso lhe dá credibilidade, o que ele diz passa a ter força de verdade.

Refletindo sobre a figura de Hernán Cortés, representada por ele, quer-se mostrar crível, heroico e valoroso, que age apenas pelo interesse de seu rei e de seu Deus:

Nas cartas de Cortés é possível perceber, num primeiro momento, duas influências narrativas que podem ser identificadas respectivamente com o "mundo de fora" e com o "mundo de dentro" do autor: a narrativa religiosa providencialista e a cavalheiresca, mesmo que as duas não possam ser separadas, pois ambas se constituem como parte integrante de uma mesma representação a respeito de Cortés, ou seja, o cavaleiro cristão. (PORTUGAL; MORAIS, 2010, p. 89)

Ele constrói a imagem de si que deseja ver espraiada, lavrada nos registros históricos, esculpida para seu rei e cinzelada no futuro. Em entrevista, diz o historiador francês Christian Duverger: "Insisto que a necessidade de se esconder em um personagem fictício era lógico, em consequência das perseguições de Carlos V, o que não se passa com outros cronistas que eram favoráveis às ações da coroa. São dois elementos, um político e outro literário que, juntos, tornam esse caso excepcional.” (JOSÉ, 2014, p. 542).

\section{4- $\mathrm{O}$ que é verdade?}

A obra?-História Verdadera de La conquista de la Nueva España.

O personagem de ficção? O escritor. O único realmente fictício seria o escritornarrador-testemunha: Bernal Díaz de Castillo. A história é verdadeira, na medida do possível.

Bernal Díaz tem uma obsessão pela palavra verdade. A verdade parece perseguilo e assombrá-lo durante seu processo de escritura. Esclarecer a verdade é uma preocupação constante dos espanhóis, principalmente Hernán Cortés e Bernal Díaz, que mencionam essa palavra constantemente e fazem um esforço para clarificar e certificar que estão dizendo a verdade. 
Diz-nos Hernán Cortés em uma carta de 18 de março de 1543, escrita ao rei de Espanha: "Que Vossa Majestade se cure da dúvida que o toma: nunca falei nada a não ser a pura verdade.” (DUVERGER, 2014, p. 191, grifo nosso).

Ele afirma que o que tem escrito é estritamente verdade, em detrimento a outras versões que o rei possa ter ouvido.

Vamos discutir a verdade que se pressupõe, História verdadeira contenha. A ideia de verdade se dá desde o início do texto, desde quando o autor dá título a sua obra: $A$ verdadeira história de a conquista de Nova Espanha. E, a partir do título ele menciona a palavra "verdade", e essa intenção de dizer somente a verdade é proclamada, muitas vezes, através de todo o trabalho.

Em Duas imagens de Hernán Cortés: uma conversa com Christian Duverger, Maria Emília Granduque José (2014) pergunta a Duverger o que é a verdade. Duverger responde:

Não sei se a noção de verdade é um tema levado em conta pelos historiadores da época. Acredito que a história sempre é uma aproximação de fatos, normalmente é uma apresentação dos fatos que dá sentido a uma ação humana. [...] Mas não sei se houve entre os historiadores da época, que são os cronistas, uma preocupação ao redor do tema da verdade, então essa ideia de que Cortés considera o tema de maneira concreta, construindo uma oposição entre os testemunhos oculares e os historiadores de gabinete, é muito novo, porque normalmente os cronistas fazem uma espécie de síntese ou trabalho de compilação de documentos. [...] De outra forma, considero que Cortés tem uma visão muito mais desenvolvida da problemática da história, atentando para duas maneiras de se fazer a história: através de testemunhos oculares ou através de documentos escritos. É uma espécie de oposição entre a oralidade e o escrito, que é muito interessante. (JOSÉ, 2014, p. 539).

Duverger se refere, respondendo à Maria Emília Granduque José (2014), à verdade contida nessas obras, pois que ele considera que foi Hernán Cortés quem frisou a palavra verdade para dar credibilidade e confiança ao seu trabalho:

Isso, no entanto, é muito particular, normalmente, os testemunhos dizem "vou contar o que digo" e os historiadores dizem "o que encontrei nos arquivos foi isso", mas não colocam o problema da 
verdade; quem coloca é Cortés, para dissimular. (JOSÉ, 2014, p. 539, grifo nosso).

Bernal Díaz insiste que leu outros textos dos mais diversos autores que deram sua versão da conquista e garante que esses estavam contando, não o que viram, mas o que ouviram dizer, porque não estavam presentes e não conviveram no dia a dia com a expedição. Assim nos esclarecem Duarte e Cordiviola (2014):

Dentre essas outras escrituras se encontram as de Gómara, Las Casas, Cortés e tantos outros. O maior rival do conquistador é o espanhol Francisco López de Gómara que escreveu sobre a Conquista da Nova Espanha mesmo sem haver feito parte Dela, isto é, escreveu do outro lado do Atlântico. E o fato de não ter visto ou feito parte é o motivo central que usa Díaz Del Castillo em sua crônica para desprezar as outras obras referentes à Conquista da Nova Espanha.(DUARTE; CORDIVIOLA, 2014, p. 1)

Díaz Del Castillo afirmava que Gómara não contava a verdade sobre o que realmente tinha acontecido já que este não presenciara os fatos como ele, pois esse somente acompanhara os passos do conquistador espanhol, mas que não estivera presente em todos os embates e acontecimentos como ele próprio, Bernal Díaz Del Castillo, seu soldadocompanheiro do dia a dia.

A verdade não poderia estar com ninguém, exceto com quem estava lá, e pode narrar os eventos do ponto de vista do observador e testemunha. Del Castillo insiste que o que os demais escritores que escreveram sobre o que aconteceu na Nova Espanha, não estava de acordo com a verdade, vista e vivida por ele:

Mas eles não viram nem entenderam o que aconteceu, embora tenham escrito sobre isso. Os verdadeiros conquistadores e os curiosos leitores que sabem o que realmente aconteceu dirão Deles que se tudo o que eles escrevem sobre outras histórias se assemelha 
ao que ele escreveu sobre a Nova Espanha, tudo estará errado. (DEL CASTILLO, 2012, p. 9) ${ }^{6}$

Mas, concluem Duarte e Cordiviola (2014) que não se pode considerar a crônica de Bernal Díaz como verdadeira, apesar de o autor pretender que fosse, mesmo porque cada pessoa fala de suas próprias perspectivas sobre os acontecimentos, e que cada observador irá relatá-los à sua própria maneira:

A crônica do conquistador espanhol "perde sua força" quando o ouvinte pretende entendê-la como objetiva, ou melhor, uma obra que está narrando fatos reais tal e qual aconteceram, pois cada pessoa vê um único objeto (no caso de Bernal, a conquista da Nova Espanha), mas ao descrevê-lo usa de suas perspectivas e experiências pessoais. Isso não quer dizer que o objeto mudou, o que sim, muda é a visão do observador a respeito do mesmo. Sabemos que ninguém que presencia um determinado ocorrido o relata da mesma maneira, pois sempre haverá um olhar particular. Sem contar que não nos fica clara a intenção de Bernal com sua crônica, pois se a historia e os romances se confundiam pode ser que todos os recursos usados por esse conquistador foi nada mais que retórica, e não o fato de querer que seu relato fosse lido como fiel aos fatos. (DUARTE; CORDIVIOLA, 2014, p. 4)

Registra fatos, conta-os de outro ponto de vista. O narrador fala do lugar de um observador, daquele que escutou, que viu, que leu os documentos, que viu as cartas do espanhol-conquistador, que se lembra de tudo, de pormenores, de detalhes. O arquétipo do conquistador se põe a escrever e pode falar livremente de si:

Hernán elogiava pouco, mas, no entanto, soube atribuir a si próprio uma paleta de qualidades que conseguiu limitar a alguns adjetivos, decalcados de Homero. Ele é assim, volta e meia, "valoroso", "corajoso", "enérgico", “eficaz e rápido", “viril”, "prudente”, “dotado de grande coração” (DUVERGER, 2014, p. 212).

${ }^{6}$ but they neither saw nor understood what hapened even though they wrote about it. The actual conquistadors and the curious readers who know what really hapened will say of them that if everything they write about other histories resembles what they wrote about New Spain, it will all be wrong. (DEL CASTILLO, 2012, p. 9) 
Não se furta a tecer comentários elogiosos sobre si mesmo, chamar a si próprio de "feito de ferro" (DEL CASTILLO, 2012, p. 126). Percebe-se que Bernal Díaz quer, principalmente, se opor à crônica de Gómara e garantir que a sua versão seja considerada verdadeira, porque estava lá, porque viu o que se passou: “É assim que conseguimos Aguilar, e não de qualquer outro modo, como o cronista Gómara escreve sobre ele, e eu não estou surpreso, porque o que ele diz é de ouvir-dizer". (DEL CASTILLO, 2012, p. 36). ${ }^{7}$

É fato recorrente, no livro de Bernal Díaz, contar os mesmos episódios que Gómara conta e divergir desse somente em pequenos detalhes.

\section{5- Gómara e Bernal Díaz}

Assim Bernal Díaz começa sua História Verídica: "Vou escrever de forma muito clara o que eu vi e experimentei lutando, sem torcê-la de uma maneira ou outra" (DEL CASTILLO, 2012, p. 1). ${ }^{8}$ A verdade está com ele, e claramente, não com outros:

Eu estou também falando aqui em resposta ao que algumas pessoas disseram e escreveram, pessoas que não tinham conhecimento disso, nem viram, nem tinham informações reais sobre o que eles propuseram sobre este assunto exceto para falar do que é de seu gosto, a fim de obscurecer, se eles puderem, nossos muitos e notáveis serviços, para que eles não possam ser reconhecidos ou mantidos na alta estima que merecem. (DEL CASTILLO, 2012, p. 2) ${ }^{9}$

Maria Emília Granduque José (2014) escreve no artigo intitulado Duas imagens de Hernán Cortés: uma conversa com Christian Duverger, resultado de uma entrevista com o autor que questiona a autoria da Historia verdadera de la conquista de Nueva España, e conclui ser o

\footnotetext{
7"This is the way we got Aguilar, and not in any other, as the chronicler Gómara writes about him, and I am not surprised, because what he says is from hearsay." (DEL CASTILLO, 2012, p. 36)

8 "I will write very plainly what I saw and experienced fighting in it, without twisting it one way or another" (DEL CASTILLO, 2012, p. 1).

${ }^{9} \mathrm{I}$ am also speaking here in response to what some people have said and written, people who had no knowledge of it, nor saw it, nor had real information about what they have put forward on this matter except to speak of what is to their taste, in order to obscure, if they can, our many and remarkable services, so they might not be renowned or held in the high esteem they deserve. (DEL CASTILLO, 2012, p. 2)
} 
próprio conquistador Hernán Cortés o autor de tal Historia, no momento em que está proibido por Carlos V de escrever e publicar suas memórias.

Meu livro faz referência ao preâmbulo escrito por Gómora na sua Historia da conquista de México, no qual não considera os testemunhos como historiadores porque, para ele, o historiador sabe investigar nos arquivos e ordenar as matérias, já os testemunhos oculares, somente contam suas histórias. (JOSÉ, 2014, p. 539).

Assim Duverger se refere a Bernal Díaz, Cortés e Gómara:

Cortés construiu sua crônica, que ao final é dupla, através de Francisco López de Gómora, para ter a dimensão escrita e de arquivos e, em contrapartida, a dimensão ocular, que é a de Bernal Diaz Del Castillo, que para mim é fruto absolutamente da pluma de Cortés. (JOSÉ, 2014, p. 539).

Teria sido um ardil do escritor de História Verdadera de La conquista de la Nueva España se contrapor a Gómara para copiar-lhe a história? Assim nos fala Duverger: "Há, pois, uma suspeita. A diatribe anti-Gómara de Díaz Del Castillo não seria um artifício? Uma espécie de cisco no olho, destinado a desviar a atenção do leitor? Uma astúcia que permitiria forjar, mediante módica soma, uma originalidade?” (DUVERGER, 2014, p. 99).

Cortés convida Gómara a morar com ele: "Em 1543 [...] ele acompanha o marquês do Vale a Validoid." (DUVERGER, 2014, p. 221).

Assim nos fala Lacroix (2007), sobre Gómara ter morado com Hernán Cortés, o que também salientou Duverger (2014) em seu livro:

A bistória da conquista do México constitui a segunda parte do História geral das Índias, como já indicamos. Podemos pensar que a ideia principal de Francisco López de Gómara era escrever apenas sobre o conquista do México, mas para localizá-lo no contexto americano, ele decidiu primeiro se refere a tudo o que aconteceu na América. Dizemos isso porque os dois textos foram escritos durante sua residência na casa de Hernán Cortês e, é claro, que nas conversas com ele e nas informações coletadas de outros conquistadores, 
ele nasceu com o desejo de escrever e dar a conhecer tudo relacionado ao desempenho da Extremadura em terras mexicanas. (LACROIX, 2007, p. IX, grifo nosso, tradução nossa.). ${ }^{10}$

Lacroix (2007), em seu prólogo, nos assegura que Bernal Díaz não conseguiria escrever se não houvesse o livro de Gómara. Gómara não teria escrito seu livro se não fosse Hernán Cortés que o ditou durante o tempo em que ele morou com Hernán Cortés.

Las Casas (2006) escreve: “Gómara, clérigo que escreveu a História de Cortés, que morava com ele em Castela, já era Marquês, não viu nada, nem nunca esteve nas Índias, e não escreveu nada além do que o próprio Cortes disse a ele." (LAS CASAS , 2006, p. 528, grifo nosso, tradução nossa). ${ }^{11}$

São muitas as opiniões de que Bernal Díaz não poderia ter escrito seu livro, tão completo e detalhado cronologicamente, tantos anos depois, sem ter um arquivo abastecido, sem conhecimento universitário e sem uma cultura equivalente.

Não ocorreu a Lacroix (2007), apesar de seu comentário, que se Bernal se baseou em Gómara para escrever sua história, que não tinha participado das expedições com Cortés, que Cortés tenha sido o mentor por trás dos dois livros; que Bernal Díaz não tenha escrito Historia verdadera de la conquista de la Nueva-España, que o escritor fosse outro, mais provável, ou seja, Hernán Cortés.

Explica Duverger (2007) a duplicidade do trabalho de Hernán Cortés, enquanto Gómara residiu com ele: Gómara escreveria o que Cortés lhe passava e em outra parte do seu tempo, dedicava-se a escrever Historia verdadera:

10 "LA HISTORIA de la conquista de México" constituye la parte segunda de la Historia general de Indias, como ya hemos indicado. Podemos pensar que la idea primaria de Francisco López de Gómara fue escribir sólo sobre la conquista de México, pero para ubicarla en el contexto americano, decidió referirse primero a todo lo acontecido en América. Decimos tal cosa porque los dos textos los escribió durante su residencia en la casa de Hernán Cortés y por supuesto que de sus pláticas con él, y de informaciones recabadas de otros conquistadores, le nació el deseo de escribir y dar a conocer todo lo relativo a la actuación del extremeño en tierras mexicanas. (LACROIX, 2007, p. IX).

11 "Gómara, clérigo que escribió la Hitoria de Cortés, que vivió com é en Castilla siendo ya Marquês y no vido cosa ninguna, ni jamás esttuvo en las Indias, y no escribió cosa sino lo que el mismo Cortés le dijo.” (LAS CASAS, 2006, p. 528). 
Durante as sessões de trabalho, o conquistador fornece informações para sua escrita, seguindo uma trama cronológica; Gómara toma notas, depois volta para seu gabinete; ei-lo então que redige, passa a limpo, ordena a matéria das entrevistas no calor da memória. Enquanto isso, Cortés, trabalhando no mesmo conteúdo, dá voz a seu soldado raso, não hesitando em repreender a versão oficial e elitista de Gómara. Evidentemente, Cortés guarda para sua criatura fictícia, o melhor de suas observações, as histórias saborosas [...] $\mathrm{O}$ texto de seu falso conquistador soa justo porque tudo é verdadeiro. (DUVERGER, 2014, p. 223, grifo nosso).

Essas versões conhecidas da História do México seriam uma versão de um único manancial: Hernán Cortés.

(...) em relação a Cortés, em relação a Bernal Díaz e, ainda, o que para mim é muito importante, em relação ao problema do controle da informação por Cortés. O que diz meu livro é que temos as Cartas de Relación escritas por Cortés, depois a versão produzida ao final de sua vida assinada pelo soldado Bernal Díaz, que é o duplo de Cortés, temos a história produzida por Gómora a partir da consulta dos arquivos de Cortés que ficavam na sua casa, em Valladolid, e temos uma quarta obra, a de Cervantes de Salazar ${ }^{12}$ - e meu livro explica de maneira bem clara que este autor frequentou a academia de Cortés e, depois da morte do conquistador, viajou para as Índias com o encargo de escrever uma crônica sobre a Nova Espanha. A respectiva crônica também se trata de um texto cortesiano, o que significa que citar Cervantes de Salazar para comprovar Bernal Díaz, para comprovar Gómora ou para comprovar Cortés, utiliza-se omesmo ponto de partida, a mesma fonte. Nesse sentido, espero que meu livro possa induzir a uma investigação mais longa, diretamente voltada para os textos de arquivos, porque até o momento temos somente a versão de Cortés. (JOSÉ, 2014, p. 539).

\footnotetext{
${ }^{12}$ Francisco Cervantes de Salazar foi um cronista espanhol que esteve no México, em 1551. Dessa experiência em terras americanas, escreveu, dentre outras obras, a Crónica de la Nueva España, escrita entre 1557 e 1564. Como letrado, também foi um dos tradutores e comentaristas do humanista español Juan Luis Vives. Próximo de Cortés, Salazar pôde redigir sua obra a partir de informações fornecidas pelo próprio conquistador e pela consulta das cinco Cartas de Relación, além, claro, de sua percepção particular sobre o que presenciou no México. (JOSÉ, 2014, p. 547).
} 
As verdades e histórias contidas nas cartas de relación, em Historia verdadera de la conquista de la Nueva-España, em De La conquista de México e em Crónica de la Nueva España, teriam se originado em uma única mente e vertente; a de Hernán Cortés.

\section{Romance de cavalaria}

Segundo Sérgio Buarque de Holanda "é fora de dúvida que os romances de cavalaria constituíram a leitura dileta e a inspiração de muitos conquistadores espanhóis" (BUARQUE DE HOLANDA, 1994, p. 33).

Duverger (2014) escreve que muitos romances de cavalaria certamente acompanharam os conquistadores em suas sacolas e alforjes, quem sabe na de Hernán Cortés. Já mencionamos o amor que este espanhol nutria pelos romances medievais, e talvez o sonho de colocar em prática os ideais da cavalaria andante, representar o cavaleiro perfeito, dos bons e gloriosos tempos de Lancelote, de Amadis de Gaula e de todos os grandes paladinos europeus. Essa semelhança da narrativa de Cortés com as novelas de cavalaria, essa recorrência ao heroico, é percebida por Portugal \& Morais:

Em seus registros, Cortés narrou suas aventuras, seus amores, sua infidelidade amorosa, seus feitos que ora mostram piedade e que ora os transforma no cavaleiro impiedoso. De qualquer forma, sempre se constrói, em sua narrativa, o cavaleiro heroico, capaz de fazer tudo, de realizar os maiores atos, em nome de Deus e da coroa espanhola. (PORTUGAL; MORAIS, 2010, p. 90)

O mesmo se depreende de Bernal Diáz Del Castillo ao ler sua Historia verdadera de la conquista de la Nueva-España. Esse retorno ao relativo aos heróis da cavalaria para se referir aos acontecimentos até à entrada em Tenochtitlán, nessa narrativa, também é percebida por Portugal \& Morais:

Além das cartas de Hernán Cortés, a obra do soldado cronista Bernal Díaz Del Castilho, Historia verdadera de la conquista de la Nueva España, também exaltou a figura do líder espanhol. Apesar de Bernal Díaz também enaltecer a ação do grupo e dos soldados, ou seja, do coletivo, toda a narrativa foi centrada na figura de Cortés, sendo que 
o tom de aventura cavalheiresca e cristã permanece em toda a obra, reforçando e ajudando a construir a representação heroica a respeito dos espanhóis. (PORTUGAL; MORAIS, 2010, p. 91)

Quando um autor faz essa afirmação: "Dissemos que parecia as coisas encantadas que eles falam no livro de Amadis ${ }^{13}$ por causa das grandes torres..." (DEL CASTILLO, 2008, p. 189, grifo nosso) ${ }^{14}$ ele está se confessando leitor e amante do autor a que se refere. Bernal Díaz compara Tenochtitlán, a cidade asteca em que entravam com as paisagens encantadas em que transitava o personagem Amadis do livro de Garcí Rodríguez de Montalvo.

Sobre esse amor ao espírito medieval das novelas de cavalaria, que se sabe, Hernán Cortés era amante, e que também transparece no livro Historia verdadera de la conquista de la Nueva-España, escreve Duverger:

Díaz encontra apenas um elemento de comparação: os encantamentos os livros de Amadís. Os romanos de cavalaria estavam no espírito da época. A gesta de Amadís de Gaula, o famoso "Beltendros", o filho do rei francês ${ }^{15}$ puramente fictício, é uma obra escrita em castelhano, que teve grande difusão na Espanha durante o século XVI. (DUVERGER, 2014, p. 130-131).

\footnotetext{
${ }^{13}$ Amadis de Gaula é o mais célebre exemplar ibérico de um dos géneros literários mais apreciados e lidos na Idade Média europeia, a novela ou romance de cavalaria. Inserindo-se na tradição artúrica (o universo cujas personagens mais célebres são o rei Artur e os cavaleiros da Távola Redonda, de um ciclo geralmente conhecido como A Demanda do Santo Graal), Amadis é indiscutivelmente uma criação peninsular, muito embora a sua datação e o seu autor continuem a levantar inúmeros problemas (brevemente referidos mais adiante). A essa tradição artúrica deve Amadis de Gaula a sua estrutura, universo e valores (um mundo de aventuras cavaleirescas num universo de maravilha), mas também, por exemplo, o espaço (Londres, Windsor, Bristol são espaços de eleição, bem como a Normandia ou mesmo a Dinamarca e a Noruega; quanto a Gaula poderá corresponder quer a Gales, quer à Bretanha Francesa, ou Pequena Bretanha). Inserindo-se, pois, nesta fecunda tradição literária medieval, Amadis é, no entanto, uma criação original, que ultrapassou largamente, aliás, as fronteiras da Península Ibérica e se transformou num dos romances de cavalaria mais lidos na Europa até, pelo menos, ao século XVII.

Tradução de Graça Videira Lopes, a partir do original castelhano de Garcí Rodríguez de Montalvo; A edição seguida nesta tradução foi a de Juan Manuel Cacho Blecua, 2 vols, Madrid, Ediciones Cátedra, 1996, p. 163.

14 "We said it looked like the enchanted things they tell of in the book of Amadís because of the great towers and cus and buildings that are in the water, all built of stonemasonry." (DEL CASTILLO, 2008, p. 189).

${ }^{15}$ Aqui se começa o primeiro livro do esforçado e virtuoso cavaleiro Amadis, filho do rei Periom de Gaula e da rainha Elisena, o qual foi corrigido e emendado pelo honrado e virtuoso cavaleiro Garcí-Rodríguez de Montalvo, regedor da nobre vila de Medina del Campo. (Tradução de Graça Videira Lopes, a partir do original castelhano de Garcí Rodríguez de Montalvo; 1963, p. 3, grifo nosso.)
} 
Além disso, Duverger (2014) se refere a que Bernal Díaz também cita outros dois romances de sua época. Nos conta ele que, quando os espanhóis atingiram a baía de San Juan de Ulua, um dos tenentes de Hernán Cortés recita a primeira estrofe do romancero Cata Francia, Montesinos e durante o episódio da Noche Triste um soldado recita uma estrofe do poema Romance de Néron y el incendio de Roma. (p. 131-134)

Escreve Duverger: "Simultaneamente, Díaz realiza uma estrofe em homenagem a Cortés, no estilo das cantigas de cavalaria.” (2014, p. 135) Como seria possível que um soldado rústico como Bernal Díaz tivesse tal estilo? Como se justificar tal cultura clássica e contemporânea no soldado de Hernán Cortés, cultura que era pertencente ao clero e à aristocracia? O próprio livro atribuído a Bernal Díaz del Castillo, sua narrativa cheia de conhecimentos clássicos o desqualificam para ser o autor de Historia verdadera de la conquista de la Nueva-España.

\section{Conclusão}

Chegamos ao final desse artigo, com um pensamento a remoer, que se origina na declaração de Christian Duverger (JOSÉ, 2014, p. 546) em entrevista já mencionada anteriormente: "há uma construção na história feita pelos historiadores e devemos desconstruíla, considerando também porque se construiu assim o mito Bernal Díaz e a imagem de Cortés."

Christian Duverger conclui seu livro indicando que todos os indicativos apontados e estudados, apontam para o nome de Hernán Cortés como autor de Historia verdadera de la conquista de la Nueva-España e de que Bernal Díaz del Castillo não seria nada mais do que um pseudônimo criado pelo próprio Hernán Cortéz. Isso, mudaria a forma pela qual vemos Hernán Cortés e radicalmente a de Bernal Díaz del Castillo, pensado como um homem que se declarava inculto ter escrito uma obra grandiosa, fonte de valor incalculável, que servia de ponto de partida para qualquer pesquisa sobre a conquista do México e os 
personagens que dela fizeram parte. Historia verdadera de la conquista de la Nueva-España orienta trabalhos historiográficos e acadêmicos que tem se valido dela para efetuar suas pesquisas, mas a partir do livro de Christian Duverger há que se ter um olhar mais crítico, mais inquiridor quando formos nos valer dessa obra e talvez, de todas as obras históricas. Importante lembrar que como disse Duverger em sua entrevista à estudiosa Maria Emília Granduque José que "a verdadeira pesquisa deve fazer perguntas a cada linha de cada documento", devemos sempre perguntar o que está por trás das palavras escritas.

\title{
CORTÉS OR BERNAL DÍAZ? \\ THE MYSTERY ABOUT THE TRUE AUTHOR BY TRUE HISTORY OF THE CONQUEST OF NEW SPAIN
}

\begin{abstract}
There is a text of impressive representations in the style of epic and there is a shareholder to Know and why not to say, understand what it was to conquer of Mexico. Christian Duverger (2014) dedicated himself to study the authorship of the True History of The Conquest of New Spain, by Bernal Díaz Del Castillo. This critical examination of the figures of Hernán Cortés and Bernal Díaz del Castillo assists in the examination of historical versions that focus not only on the battles of the conquest but also on their characters. In Cortés and bis double research on a mystification, Duverger questions the authorship of one of the main sources of research on the period, Bernal Díaz Del Castillo's book.
\end{abstract}

KEYWORDS: Christian Duverger. Cortés and his double-research on a mystification. The True History of the Conquest of New Spain. Bernal Diaz del Castillo. Hernán Cortes.

\section{REFERÊNCIAS}

APLEBY, Joyce; HUNT, Lynn; JACOB, Margaret. Telling the truth about history. Norton \& Company, 1995.

BUARQUE DE HOLANDA, Sérgio. Visão do paraíso. São Paulo: Brasiliense, 1994.

DEL CASTILLO, Bernal Díaz. The True History of the Conquest of New Spain. Translated, with an Introduction and Notes, by Janet Burke and Ted Humphrey. Indianapolis/Cambridge: Hackett Publishing Company, Inc., 2012.

. The History of the Conquest of New Spain by Bernal Diaz del Castillo. Albuquerque: University of New Mexico Press. 2008. 
DUVERGER, Christian. Cortés e seu duplo-pesquisa sobre uma mistificação. São Paulo: Editora Unesp, 2014.

GÓMARA, Francisco Lopez. De La conquista de México. Barcelona: Linkgua ediciones S.L. 2009.

JOSÉ, Maria Emilia Granduque. A presença de Malinche nas crônicas de indias do século XVI. Franca, 2011. Disponível no link: https://repositorio.unesp. br/bitstream/handle/11449/93224/jose_meg_me_fran.pdf?sequence $=1$ \&isAllowed $=\mathrm{y}_{\text {. }}$

JOSÉ, Maria Emília Granduque. Duas imagens de Hernán Cortés: uma conversa com Christian Duverger. Anos 90, Porto Alegre, v. 21, n. 40, p. 535-549, dez. 2014.

LACROIX, Jorge Gurría. Historia de la conquista de México - PRÓLOGO Y BIBLIOGRAFÍA In: GÓMARA, Francisco López de. HISTORIA DE LA CONQUISTA DE MÉXICO. Venezuela: Ayacucho, 2007. p. IX- XXXII.

LAS CASAS, Bartolomé De. Bartolomé de las Casas Brevísima relación de la destrucción de las Indias. Edición y notas José Miguel Martínez Torrejón Prólogo y cronologia Gustavo Adolfo Zuluaga Hoyos. Medellín. Colombia: Fundación Biblioteca Virtual Miguel de Cervantes y Universidad de Alicante, 2006.

MORAIS, Marcus Vinícius de. Hernán Cortés: a memória do conquistador. Anais do XXVI Simpósio Nacional de História - ANPUH, São Paulo, julho 2010.

PORTUGAL, Ana Raquel; MORAIS Marcus Vinícius de. HERNÁN CORTÉS E FRANCISCO PIZARRO: História e Memórias. Temas \& matizes - Vol. 9 - No 18, 2010. p. 85-110.

CERVANTES DE SALAZAR, Francisco. Crónica de la Nueva España. Madrid: Hispanic Society of America, 1914.

Recebido em: 02/09/2019. Aprovado em: 28/12/2019. 